\title{
Asymmetry In U.S. State Unemployment Rates
}

Benjamas Jirasakuldech, (Email: bjirasak@pacific.edu), University of the Pacific Sean Snaith, (Email: ssnaith@pacific.edu), University of the Pacific

\begin{abstract}
This paper examines the nature of asymmetry of U.S. state unemployment rates using the time reversibility test developed by Ramsey and Rothman (1996). These authors and others have found asymmetry in aggregate unemployment rates in this study we examine whether or not these results extend to state level unemployment series. Alaska, District of Columbia, Hawaii, Louisiana, Missouri, Montana, and Puerto Rico, exhibit changes in unemployment rates that are symmetric. California, Georgia, Kansas, and North Carolina, show evidence of asymmetry of the change in unemployment rates due to non-linearity in the model. Unemployment rate asymmetry documented in other states is attributable to non-Gaussian errors. Asymmetric patterns documented in most states are consistent with the fast-up and slow-down dynamics observed in aggregate unemployment data.
\end{abstract}

\section{INTRODUCTION}

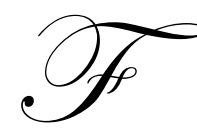

ollowing the pioneer work of Burn and Mitchell (1946), economists have long been interested in the asymmetry in business cycles and many U.S. economics variables. It has been well documented that many U.S. macroeconomic variables exhibit a prolonged periods of expansion which are longer and slower than the contractionary period. One of the macroeconomic time series that have generated much attention among economists is the unemployment rate. The presence of asymmetry in unemployment rate, or the lack thereof has an important implication for modeling the labor market. Since the use of Markov chain model by Neftci (1984) in examining the asymmetry in aggregate U.S. unemployment rate, subsequent research include Falk (1986), Rothman (1991), Sichel (1993) and Ramsey and Rothman (1996) have investigated the asymmetric unemployment behavior through the use of new statistical non-structural techniques.

One of the statistical techniques that have been widely implemented in examining the asymmetry in economic time series is the time reversibility test developed by Ramsey and Rothman (1996). Time reversibility test is superior to other conventional tests for asymmetry because it (1) determines the type of mechanism generating the stochastic process of economic time series and (2) identifies the forms of non-linear structure which left undiscovered by other techniques (Rothman, 1992). ${ }^{1}$

Most of previous research has examined the asymmetry in the unemployment in the U.S. and other developed countries at the aggregate level. This paper examines the presence of asymmetry in the U.S. unemployment rates at the state level, employing the time reversibility test developed by Ramsey and Rothman (1996). Regional differences in labor markets and variation in the industrial structure of the economies of individual states may give rise to patterns of asymmetry in unemployment rates that differ from the behavior of unemployment in the aggregate. The asymmetric properties revealed will provide insights for regional economists and policy makers providing evidence for the theoretical modeling of labor markets as well as guidance for designing appropriate forecasting models of state level unemployment.

\footnotetext{
${ }^{1}$ Through Monte Carlo simulation, Rothman (1992) show that time reversibility test is more powerful than the non-linear BDS (Brock, Dechert, and Scheinkman (1988) test and Hinich's (1982) bispecturm test in detecting for non-linear structure.
} 
Out of 50 states, the District of Columbia and Puerto Rico, seven states show changes in the level of unemployment rates that are symmetric or time reversible. These seven include Alaska, District of Columbia, Hawaii, Louisiana, Missouri, Montana, and Puerto Rico. Four of the states; California, Georgia, Kansas, and North Carolina show evidence of asymmetry in the change in unemployment rates due to non-linearity in the functional form of the model. Unemployment rate asymmetry documented in other states are due to the non-Gaussian but linear model. Asymmetric patterns found in most states exhibit the fast-up and slow-down dynamic which is consistent with the results of U.S. aggregate unemployment rates documented by Ramsey and Rothman (1996).

The rest of the paper is organized as follows: Section II provides a brief literature review on asymmetry in economic time series including the unemployment rate. Section III discusses the time reversibility techniques. Section IV describes the data and empirical results. Section V summarizes and concludes.

\section{LITERATURE REVIEW}

Prior research has examined the dynamic asymmetries in many macroeconomic time series, including the unemployment rate in the U.S., using diverse statistical techniques. Durland and McCurdy (1994) implemented Hamilton's (1989) non-linear Markov-switching model to test for the presence of non-linearity and asymmetry in U.S. GNP growth rate. They find strong evidence of non-linearity and an asymmetric pattern in the growth rate of GNP between recessionary and expansionary periods. Using time reversibility technique, Ramsey and Rothman (1996) find evidence of time irreversibility or asymmetry in annual U.S. unemployment rates during 1890-1988. The asymmetric behavior is attributed to non-linearity in the model with Gaussian innovations. Koop and Potter (1999) used non-linear and Bayesian methods in modeling the U.S. unemployment rate. Examination of their generalized impulse responses showed that a decrease in unemployment rate response to positive shocks is greater in magnitude than an increase in unemployment rate response to negative shocks. They concluded that dynamic behaviors of unemployment rate are asymmetric where an increase is sudden but a decrease is gradual.

The issue of dynamic asymmetries in business cycle and macroeconomic time series has also been investigated for data from economies other than the U.S. Holly and Stannett (1995) tested for asymmetric dynamics in U.K. consumption by employing BDS statistics and Sichel's steepness and deepness statistical tests. They found evidence of deepness but not steepness asymmetry in consumers' expenditure. In 2001, Bodman applied the triples test and the BDS non-linearity test to several Australian macroeconomic variables. He found evidence of nonlinearity and steepness asymmetry in consumer price index, M3, and unemployment rate. Using a Markov chain process, skewness test, and time reversibility test, Kohns (2001) tested for asymmetry in unemployment data in British, Germany, and U.S. The empirical results suggested that unemployment rates of these three countries exhibit steepness asymmetry of quick increase but slow decrease.

\section{METHODOLOGY}

Time reversibility test developed by Ramsey and Rothman (1996) is employed to empirically examine the pattern of U.S. state unemployment rates. The time reversibility (TR) test was originally designed to investigate the asymmetric nature of business cycles and many macroeconomic variables. A business cycle is deemed asymmetrical if the duration of upturns is longer than the duration of downturns.

A time series $\left\{X_{t}\right\}$ is time reversible if for every positive integer $n$, every $t_{1}, t_{2}, \ldots \ldots \ldots . ., t_{n} \in R$, and all $m \in N$, the vectors $\left(X_{t_{1}}, X_{t_{2}}, \ldots \ldots \ldots X_{t_{n}}\right)$ and $\left(X_{-t_{1}+m}, X_{-t_{2}+m}, \ldots \ldots \ldots \ldots, X_{-t_{n}+m}\right)$ have the same joint probability distributions. ${ }^{2}$

The time reversibility (TR) test is conducted by testing for the equality between certain pair of moments from its joint probability distributions of a time reversible time series $\left\{X_{t}\right\}$. Time series $\left\{X_{t}\right\}$ is time reversible if

\footnotetext{
${ }^{2}$ The formal definition of time reversibility is that for any time reversible time series, the probabilistic structure of a series going forward and backward in time should be the same.
} 


$$
\begin{aligned}
& E\left[X_{t}^{i} \cdot X_{t-k}^{j}\right]=E\left[X_{t}^{j} \cdot X_{t-k}^{i}\right] \text { or, } \\
& \gamma_{i, j}=E\left[X_{t}^{i} \cdot X_{t-k}^{j}\right]-E\left[X_{t}^{j} \cdot X_{t-k}^{i}\right]=0, \text { for all } i, j, k \in N .
\end{aligned}
$$

The TR test statistic is the difference between a sample estimate of the symmetric bicovariance function of a mean zero stationary time series $\left\{X_{t}\right\}$ with $T$ observations,

$$
\begin{aligned}
& \hat{\mathrm{B}}_{2,1}(k)=(T-k)^{-1} \sum_{t=k+1}^{T} X_{t}^{2} \cdot X_{t-k} \text { and } \\
& \hat{\mathrm{B}}_{1,2}(k)=(T-k)^{-1} \sum_{t=k+1}^{T} X_{t} \cdot X_{t-k}^{2}, \\
& \hat{\gamma}_{2,1}(k)=\hat{\mathrm{B}}_{2,1}(k)-\hat{\mathrm{B}}_{1,2}(k)
\end{aligned}
$$

for various integer values of $k$. Under the null hypothesis that $\left\{X_{t}\right\}$ is time reversible, the expected value of $\hat{\gamma}_{2,1}(k)$ should be zero for all lag $k$. To test for an asymmetric pattern, the TR test is applied first directly on the change in the unemployment rates of each state. The TR test statistic is standardized by $\operatorname{var}\left[\hat{\gamma}_{2,1}(k)\right]^{1 / 2}$, which is obtained through Monte Carlo simulation.

The time reversibility test requires the time series being investigated be a stationary process. Prior to the tests for asymmetry, Augmented Dickey-Fuller and Phillips-Perron unit root tests are performed on each state unemployment rate to test for stationarity of the economic series.

Since there is no exact small sample expression for $\operatorname{var}\left[\hat{\gamma}_{2,1}(k)\right]^{1 / 2}$, the empirical sample distribution of TR test statistic is generated through Monte Carlo simulations. ARMA model is first identified and estimated for change in unemployment series of each state. A Monte Carlo simulation is performed 1,000 times to obtain the estimated the standard deviation of $\hat{\gamma}_{2,1}(k)$ for each ARMA model. The significance of the standardized TR test statistics, $\hat{\gamma}_{2,1}(k) / \operatorname{var}\left[\hat{\gamma}_{2,1}(k)\right]^{1 / 2}$, for each lag is ascertained using the empirical sample distribution generated via Monte Carlo simulations.

The joint test for a set of $\hat{\gamma}_{2,1}(k)=0$ is also performed based on the time reversibility portmanteau statistic,

$$
P_{m, n}=\sum_{k=m}^{n}\left[\hat{\gamma}_{2,1}(k) / \operatorname{var}\left[\hat{\gamma}_{2,1}(k)\right]^{1 / 2}\right]^{2}
$$

where $P_{m, n}$ is distributed as $\chi^{2}$ with $n-m+1$ degree of freedom.

To further identify the underlying source of asymmetry or time irreversibility in state unemployment, the time reversibility test is conducted on the ARMA residuals from the fitted model. Ramsey and Rothman (1996) show that asymmetry can stem from two sources: (1) the underlying model is nonlinear but the innovations are normally distributed (Type I time irreversibility); or (2) the underlying model is linear but the innovations follow non-Gaussian probability distribution (Type II time irreversibility). To differentiate between Type I and Type II time irreversibility, the TR test statistics are calculated on the ARMA residuals for each state, and are standardized by the $\operatorname{var}\left[\hat{\gamma}_{2,1}(k)\right]^{1 / 2}$ where $\operatorname{var}\left[\hat{\gamma}_{2,1}(k)\right]^{1 / 2}$ is calculated via Theorem 2 in Ramsey and Rothman (1996) 
Theorem 2: Let $\left\{X_{t}\right\}$ be a stationary sequence of independently and identically distributed random variables (IID standard errors) for which $E\left[X_{t}\right]=0 \forall t$ and assume $E\left[X_{t}^{4}\right] \prec \infty$. Then,

$$
\begin{aligned}
& \operatorname{var}\left[\hat{\gamma}_{2,1}(k)\right]^{1 / 2}=2\left(\mu_{4} \mu_{2}-\mu_{3}^{2}\right) /(T-k)-2 \mu_{2}^{3}(T-2 k) /(T-k)^{2}, \\
& \text { where } \mu_{2}=E\left[X_{t}^{2}\right], \mu_{3}=E\left[X_{t}^{3}\right] \text {, and } \mu_{4}=E\left[X_{t}^{4}\right] .
\end{aligned}
$$

If the time series process is Type I time irreversibility, the approximation via an $\operatorname{ARMA}(p, q)$ will reduce the power of the test and, hence, results in rejecting the null hypothesis of time reversibility on the residuals most of the time. Therefore, if the null hypothesis of time reversibility is rejected for both the raw data and ARMA residuals, the rejection is of Type I time irreversibility (asymmetry in the functional form of the unemployment series). On the other hand, if it is rejected on the raw data but not on the ARMA residuals, it indicates Type II time irreversibility (asymmetry in the innovations).

The signs of TR test statistic $\hat{\gamma}_{2,1}(k)$ provide information on the pattern of the up-and-down trends. If the signs of TR test statistics are positive at the initial lags, it indicates "fast-up and slow-down" asymmetric pattern. In contrast, if the signs of TR test statistics are negative at the initial lags, asymmetry of the "slow-up and fast-down" pattern is more likely. ${ }^{3}$

\section{DATA AND EMPIRICAL RESULTS}

\section{Data}

Monthly seasonally adjusted unemployment rates for all the 50 states, District of Columbia and Puerto Rico were obtained from the Bureau of Labor Statistics, http://www.bls.gov. The investigated sample period is from 1978:Q1 to 2004:Q3 for all the states, with the exception of California whose sample begins in 1980:Q1. Quarterly unemployment rates are computed as the average of the monthly unemployment rates for that particular quarter. To be consistent with Ramsey and Rothman (1996), the time reversibility test is performed on the first difference of the unemployment rate $\left(\Delta \mathrm{X}_{\mathrm{t}} \square \square\right.$ of each state to test for steepness asymmetry.

We provide descriptive statistics of the first difference of the unemployment rate series in Table 1. During the period studied, the change in unemployment rates for most of the states on average is negative. Eleven states, namely Iowa, Kansas, Minnesota, North Carolina, Ohio, Oregon, South Carolina, South Dakota, Texas, Utah, and Wyoming report the positive change in unemployment rates. The unemployment rate in Nebraska does not vary during the period studies. Puerto Rico provides the highest decrease in unemployment rate of $0.08 \%$ and Oregon shows the highest increase in unemployment rate of $0.02 \%$. The change in unemployment in Puerto Rico shows the greatest variation over the sample period and exhibits the highest standard deviation $(0.71 \%)$, while South Dakota reports the most stable labor market exhibiting the lowest standard deviation $(0.25 \%)$.

Out of fifty states, the District of Columbia and Puerto Rico, twenty-five series show asymmetry as indicated by significance of skewness coefficients. The distribution of the first difference in unemployment rates for all of these twenty-five states, except for Louisiana, is positively skewed. This implies that unemployment rate exhibits an asymmetric pattern of a quick increase during recession but a slow decrease during the expansionary phase of the business cycle. The strongest asymmetric behavior of unemployment rate exists in the state of Georgia, as evidenced by the largest skewness coefficient of 2.79. Additionally, more than half of the states under investigation show significance of high kurtosis. This suggests that, big shocks are more likely to be present in the labor market and the

\footnotetext{
${ }^{3}$ Refer to Ramsey and Rothman (1996) on the asymmetric pattern based on the sign of the TR test statistics.
} 
unemployment rate series may not be normally distributed. The Jaque-Bera test statistics provide evidence against the normal distribution for almost all of the fifty states, and the District of Columbia and Puerto Rico. ${ }^{4}$

The last characteristic of the unemployment rate series examined in Table 1 is autocorrelation. The LjungBox statistic (1978), as denoted in the final two columns labeled by Q(6) and Q(12) show that the null hypothesis of no autocorrelation of the $6^{\text {th }}$ and $12^{\text {th }}$ order are rejected for all states at the 1 percent significance level, with the exception of Georgia where the rejection occurs at the 5 percent significance level at the $12^{\text {th }}$ order. $^{5}$

\section{Time Reversibility Empirical Results}

The stationarity of the differenced unemployment rate series are confirmed via Augmented Dickey Fuller and Phillips-Perron unit root tests. The null hypothesis of a unit root is rejected at the traditional significance levels for all the states. ${ }^{6}$ Subsequent to the finding of stationarity, the change in unemployment time series of each state is used to calculate the TR test statistics for lags 1 to 10 . The maximum lag length of 10 is chosen to preserve the power of the test on one hand and to maintain enough of a time span to capture the business cycle on the other. Since the series are not independently distributed, the variances of TR test statistics are generated by Monte Carlo simulation of the hypothetical ARMA model which generated the data. The ARMA coefficients and their respective $\sigma^{2}\left(\varepsilon_{t}\right)$ are used in a Monte Carlo simulation to generate 1,000 groups of TR test statistics of each lag for each state. $^{7}$ The variances of TR test statistic are calculated from 1,000 TR test statistic using the traditional formula. The TR test statistics are then standardized by $\operatorname{var}\left[\hat{\gamma}_{2,1}(k)\right]^{1 / 2}$ obtained from Monte Carlo simulation.

Table 2 reports the results of the TR test on the differenced unemployment rates and time reversibility portmanteau statistic, $P_{1,10}{ }^{8}$ The portmanteau statistics reject the null hypothesis that $\hat{\gamma}_{2,1}(k)$ values for all 10 lags are jointly significantly different from zero for all the states with the exception of Alaska, the District of Columbia, Hawaii, Louisiana, Missouri, Montana, and Puerto Rico. Consistent with the finding of asymmetry in U.S. aggregate unemployment rate documented by Ramsey and Rothman (1996), the dynamic behavior of unemployment rates at the state level are asymmetric or time irreversible with the exception of these five states and two territories which exhibit a symmetric pattern. The $P_{l, 10}$ portmantaeu statistics reject the null hypothesis of symmetry at the $1 \%$ significance level for most states. Additionally, the unemployment rate of Michigan shows the strongest degree of asymmetric behavior with the highest value of $P_{1,10}$.

To further identify the source of asymmetry, TR tests are performed on the residuals derived from fitting ARMA model and the results are reported in Table 3. Since the residuals obtained from the ARMA model are IID, the variances of the TR test statistics are calculated using Theorem 2. The portmanteau TR test statistics jointly reject the null hypothesis of time reversibility at the 1\% level for California, and 5\% level for Georgia and North Carolina and at the $10 \%$ level for Kansas. The asymmetric behaviors of unemployment rate in California, Georgia, North Carolina, and Kansas are consistent with Type I time irreversibility where the source of asymmetry is due to nonlinearity in the functional form as opposed to non-Gaussian or asymmetric innovations. Understanding the underlying

\footnotetext{
${ }^{4}$ Unemployment rates series in thirteen states exhibit normal distribution as shown by the test statistics of skewness, kurtosis, and Jarque-Bera. They are the unemployment rates of Alaska, Connecticut, Maryland, Mississippi, Montana, New Hampshire, New Mexico, New York, Puerto Rico, South Carolina, Vermont, Washington, and Wyoming.

${ }^{5}$ Under the null hypothesis of no serial correlation, the Q-statistics, $\mathrm{Q}(\mathrm{k})$, are distributed asymptotically as chi-squared with $\mathrm{k}$ degree of freedom.

${ }^{6}$ Both the Augmented Dickey Fuller and Phillips-Perron unit root tests are performed on the models with and without trend. The results are not reported here but are available from the authors upon request.

${ }^{7}$ The results of identification of ARMA model of each state unemployment rate series are not reported here. They are available from the authors upon request. The autoregressive (AR) and the moving average (MA) terms are chosen using a number of criteria: the Akaike Information Criterion (AIC), the Schwartz Information Criterion (SBC), the absence of serial correlation in the residuals, and the significance of the coefficients on the AR or MA models.

${ }^{8} \mathrm{P}_{1,10}$ is the time reversibility portmanteau statistics similar to the Ljung Box portamanteau statistics. The time reversibility portmanteau statistic is a joint test on a set of standardized TR test statistics values. With 10 degrees of freedom, $\chi_{0.9}^{2}=15.99, \chi_{0.95}^{2}$ $=18.31$, and $\chi_{0.99}^{2}=23.20$.
} 
mechanism generating such asymmetric behavior is crucial because it provides information for modeling the unemployment rate behavior. Evidence reported here suggests that a non-linear model will provide a better representation of the dynamic behavior of the unemployment rates of California, Georgia, North Carolina, and Kansas. For the other forty-one series, the unemployment rates which are originally found to be time irreversible are time reversible when IID residuals are examined. This suggests that steepness asymmetries of these states are consistent with Type II time irreversibility where the asymmetries are caused by non-Gaussian innovations underlying a linear model. Hence, the linear model is deemed appropriate in characterizing the asymmetric behavior of these states.

Examining the sign of the TR test statistics for each lag shows that the individual TR test statistics have a positive sign for almost all of the 10 lags for those states which are found to be time irreversible, with the exception of the TR test statistics of Alaska, Arkansas, District of Columbia Oregon, Georgia, Iowa, Missouri, Montana, North Dakota, Puerto Rico and Washington which show no discernible pattern in the signs of these statistics over all 10 lags. This suggests that the unemployment of most states exhibit "fast-up and slow-down" asymmetric behavior. This is consistent with counter-cyclical asymmetry where the unemployment increases quickly during the recession but decreases slowly during the expansion phase.

\section{CONCLUSION}

Using the non-structural time reversibility test for asymmetry, this paper empirically examines the asymmetric behavior in the unemployment rates of fifty states in the U.S. including the District of Columbia, and Pueto Rico during 1978:Q1 to 2004:Q3. Out of the 50 states, Puerto Rico and the District of Columbia, the time series properties of unemployment rates for seven states are time reversible or symmetric. This group includes; Alaska, District of Columbia, Hawaii, Louisiana, Missouri, Montana, and Puerto Rico. The implications of this finding have both practical and theoretical dimensions. Practically speaking researchers interested in forecasting the unemployment rate for these states would be safe using a Gaussian ARMA approach to capture the dynamics of these series, since the times series behavior of unemployment in this group exhibits a pattern that does not depend on the stage of the business cycle. Theoretically, this result is inconsistent with the results when looking at aggregate unemployment, which show asymmetry that is fast up and slow down. These findings in the aggregate point toward models of the labor market that incorporate asymmetric adjustment costs such as search and matching models or models of hysteresis that include transaction or adjustment costs. The behavior of unemployment in this group of states appears to be inconsistent with such models that also imply asymmetry of unemployment rates.

Four of the forty-five states for which the unemployment rates are found to be asymmetric, show that the source of asymmetry is due to non-linearity in the functional form with Guassian innovations namely, California, Georgia, Kansas, and North Carolina. For these four states using linear approaches for modeling the behavior of unemployment would appear to be inappropriate. However, unemployment rates asymmetries documented in other states are attributable to a model that is linear with non-Gaussian errors. All of the asymmetric patterns found, with the exception of North Carolina, exhibit the fast-up and slow-down pattern which is consistent with the results of U.S. aggregate unemployment rates documented by Ramsey and Rothman (1996) and others.

\section{REFERENCES}

1. Bodman, P. M., Steepness and Deepness in the Australian Macroeconomy, Applied Economics 33, 375-382, (2001).

2. Brock, W.A., W. D. Dechert, and J. A. Scheinkman, A Test for Independence Based on the Correlation Dimension, Unpublished manuscript, Department of Economics, University of Wisconsin at Madison, University of Houston and University of Chicago, (1988).

3. Burns, A. F. and W. C. Mitchell, Measuring Business Cycles. New York: Columbia University Press.

4. Durland, J. M. and T. H. McCurdy, Duration-Dependent Transitions in a Markov Model of U.S. GNP Growth, Journal of Business \& Economics Statistics 12(3), 279-288, (1994).

5. Falk, Berry, Further Evidence on the Asymmetric Behavior of Economic Time Series over the Business Cycle, Journal of Political Economy 94(5), 1096-1109, (1986). 
6. Hamilton, J. D., A New Approach to the Economic Analysis of Nonstationary Time Series and the Business Cycle, Econometrica 57, 357-384, (1989).

7. Hinsch, M. J., Testing for Gaussianity and Linearity of a Stationary Time Series, Journal of Time Series Analysis 3, 169-176, (1982).

8. Holly, S. and M. Stannett, Are There Asymmetries in UK consumption? A Time Series Analysis, Applied Economics 27, 767-772, (1995).

9. Kohns Stephan, Testing for Asymmetry in British, German and U.S. Unemployment Data, Working paper, (2001).

10. Koop, G. and S. M. Potter. Dynamic Asymmetries in U.S. Unemployment, Journal of Business \& Economic Statistics 17 (3), 298-312, (1999).

11. Neftci, Salih N. Are Economic Time Series Asymmetric Over the Business Cycle? Journal of Political Economy 92, 307-328, (1984).

12. Phillips, P. C. B. and P. Perron, Testing for a Unit Root in Time Series Regression. Biometrika 75, 335-346, (1988).

13. Ramsey, J. B. and P. Rothman, Characterization of the Time Irreversibility of Economic Time Series: Estimators and Test Statistics. Manuscript, C. V. Starr Center research Report no. 88-39, Department of Economics, New York University, 1988.

14. Ramsey, J. B. and P. Rothman, Time Irreversibility and Business Cycle Asymmetry. Journal of Money, Credit, and Banking 28, 1-21, (1996).

15. Rothman, The Comparative Power of the TR Test Against Simple Threshold Models. Journal of Applied Econometrics 7, 187-195, (1991).

16. Sichel, Daniel E., Business Cycle Asymmetry: A Deeper Look, Economic Inquiry 13 (2), 291-298, (1993). 
Table 1

Summary Statistics of Quarterly Change in U.S. States Unemployment Rates 1978:Q1 to 2004:Q3 ${ }^{1}$

\begin{tabular}{|c|c|c|c|c|c|c|c|c|}
\hline & States & $\operatorname{Mean}^{2}$ & $\begin{array}{c}\text { Standard } \\
\text { Deviation }\end{array}$ & Skewness $^{3}$ & Kurtosis $^{4}$ & Jarque-Bera $^{5}$ & $Q(6)^{6}$ & $Q(12)$ \\
\hline 1 & Alabama & -0.0094 & 0.4650 & $0.4448^{*}$ & $0.9110^{*}$ & $7.16142^{* *}$ & $56.3768^{* * *}$ & $70.9251^{* * *}$ \\
\hline 2 & Alaska & -0.0340 & 0.3900 & -0.2584 & -0.0845 & 1.2110 & $47.5901^{* * *}$ & $71.7188^{* * *}$ \\
\hline 3 & Arizona & -0.0223 & 0.5624 & 0.0009 & $1.7345^{* * *}$ & $13.2886^{* * *}$ & $112.6499^{* * * *}$ & $123.7466^{* * *}$ \\
\hline 4 & Arkansas & -0.0097 & 0.2665 & -0.1430 & $3.1164^{* * *}$ & $43.2565^{* * *}$ & $34.596^{* * *}$ & $44.8433^{\text {*** }}$ \\
\hline 5 & California & -0.0003 & 0.3412 & $0.6617^{* * * *}$ & $0.9228^{*}$ & $10.6287^{* * *}$ & $87.6018^{* * *}$ & $91.5283^{* * *}$ \\
\hline 6 & Colorado & -0.0110 & 0.3983 & $0.5155^{* *}$ & $0.8105^{*}$ & $7.5976^{* *}$ & $59.5977^{* * *}$ & $70.7274^{* * * *}$ \\
\hline 7 & Connecticut & -0.0110 & 0.3254 & -0.0192 & 0.1414 & 0.0948 & $61.1884^{* * *}$ & $79.8725^{* * *}$ \\
\hline 8 & Delaware & -0.0358 & 0.3709 & $1.4075^{* * *}$ & $7.2613^{* * *}$ & $267.8764^{* * *}$ & $20.4286^{* * *}$ & $28.1661^{* * *}$ \\
\hline 9 & Columbia & -0.0075 & 0.4461 & $-0.4553^{*}$ & 0.5085 & $4.8057^{*}$ & $34.8836^{* * *}$ & $42.0678^{* * *}$ \\
\hline 10 & Florida & -0.0239 & 0.2980 & 0.0507 & $1.9669^{* * *}$ & $17.1336^{* * *}$ & $62.3844^{* * *}$ & $80.0358^{* * *}$ \\
\hline 11 & Georgia & -0.0173 & 0.4209 & $2.7882^{* * * *}$ & $20.3929^{* * *}$ & $1974.1081^{* * *}$ & $17.7199^{* * *}$ & $21.1886^{* *}$ \\
\hline 12 & Hawaii & -0.0440 & 0.3380 & $0.6487^{* * * *}$ & 0.7630 & $10.0075^{* * *}$ & $39.1875^{* * *}$ & $50.922^{* * * *}$ \\
\hline 13 & Idaho & -0.0044 & 0.4295 & 0.0456 & $2.8685^{* * *}$ & $36.3793^{* * *}$ & $34.6818^{* * *}$ & $46.7677^{* * * *}$ \\
\hline 14 & Illinois & -0.0041 & 0.4217 & $0.4976^{* *}$ & $1.2168^{* *}$ & $10.9144^{* * *}$ & $67.1761^{* * *}$ & $76.6281^{* * *}$ \\
\hline 15 & Indiana & -0.0079 & 0.4116 & $0.8043^{* * *}$ & $2.2348^{* * *}$ & $33.4895^{* * *}$ & $38.5358^{* * *}$ & $46.9601^{* * * *}$ \\
\hline 16 & Iowa & 0.0016 & 0.2783 & $0.6359^{* * * *}$ & $1.9420^{* * *}$ & $23.8025^{* * *}$ & $59.8062^{* * *}$ & $66.1017^{* * * *}$ \\
\hline 17 & Kansas & 0.0132 & 0.3071 & $1.7799^{* * * *}$ & $9.3148^{* * *}$ & $439.1915^{* * * *}$ & $45.1692^{* * *}$ & $51.1063^{* * *}$ \\
\hline 18 & Kentucky & -0.0009 & 0.3886 & $0.6949^{* * *}$ & $1.5876^{* * * *}$ & $19.6658^{* * *}$ & $56.1085^{* * *}$ & $63.7997^{* * *}$ \\
\hline 19 & Louisiana & -0.0192 & 0.4395 & $-0.4117^{*}$ & 0.3353 & 3.4920 & $56.1384^{* * *}$ & $69.3643^{\text {*** }}$ \\
\hline 20 & Maine & -0.0182 & 0.3892 & $0.6280^{* * *}$ & $2.4876^{* * *}$ & $34.3004^{* * *}$ & $34.9196^{* * *}$ & $40.4599^{* * *}$ \\
\hline 21 & Maryland & -0.0142 & 0.2664 & 0.1728 & 0.5795 & 2.0108 & $56.5051^{* * *}$ & $73.0476^{* * *}$ \\
\hline 22 & Massachusetts & -0.0148 & 0.3691 & $1.0360^{* * * *}$ & $2.7426^{* * *}$ & $52.1869^{* * *}$ & $104.0553^{* * *}$ & $128.399^{* * * *}$ \\
\hline 23 & Michigan & -0.0031 & 0.6327 & $2.6513^{* * *}$ & $14.0350^{* * * *}$ & $994.1954^{* * * *}$ & $21.0776^{* * *}$ & $34.5224^{* * * *}$ \\
\hline 24 & Minnesota & 0.0057 & 0.3146 & $0.5498^{* *}$ & $1.3368^{* * * *}$ & $13.2347^{* * *}$ & $73.3938^{* * *}$ & $83.7484^{* * *}$ \\
\hline
\end{tabular}


Table 1 (Cont.)

Summary Statistics of Quarterly Change in U.S. States Unemployment Rates 1978:Q1 to 2004:Q3 ${ }^{1}$

\begin{tabular}{|c|c|c|c|c|c|c|c|c|}
\hline & States & $\operatorname{Mean}^{2}$ & $\begin{array}{c}\text { Standard } \\
\text { Deviation }\end{array}$ & Skewness $^{3}$ & Kurtosis $^{4}$ & Jarque-Bera $^{5}$ & $Q(6)^{6}$ & $Q(12)$ \\
\hline 27 & Montana & -0.0223 & 0.2737 & 0.0955 & 0.2808 & 0.5092 & $58.9219^{* * *}$ & $87.9105^{* * * *}$ \\
\hline 28 & Nebraka & 0.0000 & 0.2852 & -0.2784 & $2.07744^{* * * *}$ & $20.43089^{* * * *}$ & $46.9958^{* * *}$ & $58.9024^{* * *}$ \\
\hline 29 & Nevada & -0.0066 & 0.4599 & 0.2985 & $1.00744^{* *}$ & $6.0571^{* *}$ & $34.1553^{* * *}$ & $45.2623^{* * *}$ \\
\hline 30 & New Hampshire & -0.0085 & 0.3955 & 0.3293 & 0.4741 & 2.9084 & $66.0177^{* * *}$ & $77.1712^{* * *}$ \\
\hline 31 & New Jersey & -0.0264 & 0.3427 & $0.8059^{* * *}$ & $1.81686^{* * * *}$ & $26.05394^{* * * *}$ & $44.8648^{* * *}$ & $52.0397^{* * *}$ \\
\hline 32 & New Mexico & -0.0044 & 0.4185 & -0.0592 & 0.5494 & 1.3953 & $120.4726^{* * *}$ & $132.0883^{* * *}$ \\
\hline 33 & New York & -0.0233 & 0.2954 & 0.2522 & 0.7940 & 3.9078 & $61.6122^{* * *}$ & $70.511^{* * * *}$ \\
\hline 34 & North Carolina & 0.0025 & 0.4260 & $1.7294^{* * *}$ & $8.0258^{* * *}$ & $337.3364^{* * * *}$ & $32.6269^{* * * *}$ & $38.5003^{* * *}$ \\
\hline 35 & North Dakota & -0.0204 & 0.2995 & 0.2287 & 0.5980 & 2.5038 & $34.9921^{* * *}$ & $40.0409^{* * *}$ \\
\hline 36 & Ohio & 0.0044 & 0.4374 & $0.9744^{* * *}$ & $3.4377^{* * *}$ & $68.9743^{* * *}$ & $38.7651^{* * *}$ & $48.0481^{* * *}$ \\
\hline 37 & Oklahoma & -0.0057 & 0.4918 & $0.7862^{* * *}$ & $2.3077^{* * *}$ & $34.4438^{* * *}$ & $58.0677^{* * * *}$ & $87.0696^{* * *}$ \\
\hline 38 & Oregon & 0.0164 & 0.4375 & $0.5012^{* *}$ & $1.7667^{* * *}$ & $18.2261^{* * *}$ & $28.2778^{* * *}$ & $32.8392^{* * *}$ \\
\hline 39 & Pennsylvania & -0.0189 & 0.3448 & 0.3323 & $0.9865^{* *}$ & $6.2492^{* *}$ & $86.4698^{* * *}$ & $93.852^{* * *}$ \\
\hline 40 & Puerto Rico & -0.0814 & 0.7139 & 0.0877 & -0.6662 & 2.0962 & 6.3868 & $26.2356^{* * *}$ \\
\hline 41 & Rhode Island & -0.0170 & 0.4323 & -0.0125 & $0.9283^{*}$ & 3.8089 & $62.0099^{* * * *}$ & $66.9346^{* * *}$ \\
\hline 42 & South Carolina & 0.0031 & 0.4295 & -0.0178 & 0.3037 & 0.4130 & $75.4782^{* * * *}$ & $81.2472^{* * *}$ \\
\hline 43 & South Dakota & 0.0069 & 0.2466 & 0.1466 & $2.2523^{* * *}$ & $22.7852^{* * *}$ & $61.8089^{* * *}$ & $100.7603^{* * *}$ \\
\hline 44 & Tennessee & -0.0107 & 0.3851 & 0.1895 & $1.9266^{* * *}$ & $17.0288^{* * *}$ & $64.037^{* * *}$ & $82.0646^{* * *}$ \\
\hline 45 & Texas & 0.0050 & 0.3322 & $0.9834^{* * * *}$ & $1.9570^{* * *}$ & $34.0026^{* * *}$ & $101.7041^{* * * *}$ & $122.4608^{* * * *}$ \\
\hline 46 & Utah & 0.0038 & 0.3694 & 0.1730 & $2.4521^{* * *}$ & $27.0869^{* * *}$ & $92.5923^{* * * *}$ & $98.6499^{* * *}$ \\
\hline 47 & Vermont & -0.0286 & 0.3442 & 0.1758 & 0.4454 & 1.4218 & $36.5359^{* * *}$ & $43.0544^{* * *}$ \\
\hline 48 & Virginia & -0.0195 & 0.3051 & $0.4920^{* *}$ & $2.023^{* * *}$ & $22.363^{* * *}$ & $53.229^{* * *}$ & $75.7847^{* * *}$ \\
\hline 49 & Washington & -0.0097 & 0.3737 & 0.1288 & 0.5356 & 1.5599 & $74.8809^{* * * *}$ & $90.2791^{* * *}$ \\
\hline 50 & West Virginia & -0.0157 & 0.6204 & $1.2934^{* * *}$ & $3.2660^{* * *}$ & $76.6686^{* * *}$ & $58.123^{* * *}$ & $60.0945^{\text {**** }}$ \\
\hline 51 & Wisconsin & -0.0019 & 0.4395 & -0.0278 & $3.1308^{* * *}$ & $43.3072^{* * *}$ & $49.0255^{* * * *}$ & $54.7249^{* * *}$ \\
\hline 52 & Wyoming & 0.0031 & 0.4641 & 0.1288 & 0.5356 & 1.5599 & $68.1355^{* * * *}$ & $71.5323^{* * *}$ \\
\hline
\end{tabular}

Notes: ${ }^{1}$ The period studies for all the states are from 1978:Q1 to 2004:Q3 except the unemployment rates for California are from from 1980:Q1 to 2004:Q3.

${ }^{2}$ Mean and standard deviations are expressed in percent.

${ }^{3}$ Asymptotic standard errors of coefficient of skewness is $(6 / \mathrm{N})^{1 / 2}$.

${ }^{4}$ Asymptotic standard errors of coefficient of excess kurtosis is $(24 / \mathrm{N})^{1 / 2}$.

${ }^{5} \rho_{\mathrm{t}}$ is the sample autocorrelation at lag $t$.

${ }^{6} \mathrm{Q}(6)$ and $\mathrm{Q}(12)$ are the Ljung-Box portmantaeu test statistic identifying the presence of sixth and twefth-order autocorrelation. Under the null hypothesis of no autocorrelation, it is distributed as $\chi^{2}$ with 6 and 12 degrees of freedom, respectively.

$7 * * *$ Indicates significance at the $1 \%$ level, ** Indicates significance at the 5\% level, and * Indicates significance at the $10 \%$ level. 
Table 2

Standardized Time Reversibility Test Statistics on U.S. States Unemployement Rates ${ }^{1}$ 1978:Q1 to 2004:Q3 ${ }^{1}$

\begin{tabular}{|c|c|c|c|c|c|c|c|c|c|c|c|c|c|}
\hline & \multirow[b]{2}{*}{ States } & \multicolumn{10}{|c|}{ Standardized TR test statistic at Lag $k^{2}$} & \multirow[b]{2}{*}{$P_{1,10}{ }^{3}$} & \multirow{2}{*}{$\begin{array}{c}\text { Rejection } \\
\text { Type }^{4}\end{array}$} \\
\hline & & $k=1$ & $k=2$ & $k=3$ & $k=4$ & $k=5$ & $k=6$ & $k=7$ & $k=8$ & $k=9$ & $k=10$ & & \\
\hline 1 & Alabama & $4.292^{* * * *}$ & $1.840^{* * * *}$ & 1.089 & 0.924 & $1.906^{* * *}$ & $3.036^{* * *}$ & $2.906^{* * *}$ & $2.054^{* *}$ & 1.052 & $2.018^{* * *}$ & $54.54^{* * * *}$ & Type II \\
\hline 2 & Alaska & 0.611 & -0.040 & -0.845 & -0.259 & 0.113 & 0.532 & 0.743 & 0.075 & -0.466 & -0.963 & 3.153 & Time Reversible \\
\hline 3 & Arizona & $3.004^{* * * * *}$ & $3.240^{* * * * *}$ & $3.974^{\text {****** }}$ & $2.545^{* *}$ & $2.423^{* * *}$ & $1.826^{* *}$ & 1.256 & $1.778^{* * *}$ & 0.936 & -0.748 & $57.18^{* * * *}$ & Type II \\
\hline 4 & Arkansas & $-3.351^{* * * *}$ & $2.415^{* * * *}$ & $2.085^{* *}$ & -0.226 & 0.559 & -0.239 & 0.031 & -0.611 & -0.250 & -0.166 & $22.29^{* * *}$ & Type II \\
\hline 5 & California & 0.286 & $3.407^{* * * *}$ & $1.763^{* *}$ & $2.185^{* *}$ & $2.853^{* * *}$ & $2.976^{* * * *}$ & $2.548^{* * *}$ & $1.730^{* *}$ & $1.682^{* *}$ & 1.235 & $50.42^{* * * *}$ & Type I \\
\hline 6 & Colorado & $2.172^{* * *}$ & $4.412^{* * * *}$ & $2.409^{* * *}$ & $2.949^{* * * *}$ & $1.304^{*}$ & 1.150 & 0.403 & -0.176 & 0.989 & -0.044 & $42.87^{\text {***** }}$ & Type II \\
\hline 7 & Connecticut & $3.497^{* * * *}$ & $2.865^{\text {***** }}$ & $2.382^{* *}$ & $2.349^{* * *}$ & $1.353^{*}$ & $1.550^{*}$ & $1.544^{*}$ & $1.627^{* *}$ & $1.106^{*}$ & $1.587^{* *}$ & $44.63^{\text {**** }}$ & Type II \\
\hline 8 & Delaware & $3.280^{* * * *}$ & $2.266^{* *}$ & $3.686^{* * * *}$ & $1.953^{* * *}$ & $2.342^{* *}$ & $1.414^{*}$ & $1.612^{* *}$ & $1.840^{* * *}$ & 1.059 & -0.999 & $48.88^{* * * *}$ & Type II \\
\hline 9 & Columbia & $-1.871^{* *}$ & -0.677 & 0.669 & $1.270^{*}$ & 0.838 & $1.287^{*}$ & 0.251 & -0.342 & -0.159 & -0.018 & 8.58 & Time Reversible \\
\hline 10 & Florida & $6.499^{\text {***** }}$ & $5.287^{* * * *}$ & $8.329^{* * * *}$ & $7.249^{* * * *}$ & $4.681^{\text {***** }}$ & $3.427^{* * * *}$ & $3.756^{* * * *}$ & $3.582^{* * * *}$ & $2.640^{\text {*** }}$ & $1.634^{*}$ & $262.34^{* * * *}$ & Type II \\
\hline 11 & Georgia & $3.532^{* * * * *}$ & 1.183 & $-6.816^{* * *}$ & $3.100^{* * * *}$ & $3.664^{* * * *}$ & $2.989^{* * * * *}$ & $1.417^{*}$ & 0.757 & $1.357^{*}$ & -0.948 & $97.62^{* * * *}$ & Type I \\
\hline 12 & Hawaii & $3.013^{* * * *}$ & 1.110 & 0.608 & 0.600 & 0.203 & -0.531 & -1.025 & $-1.347^{*}$ & -0.878 & -0.126 & 15.02 & Time Reversible \\
\hline 13 & Idaho & $2.845^{\text {***** }}$ & $5.250^{* * * *}$ & $1.930^{* * *}$ & 0.390 & $2.093^{* * *}$ & 1.110 & 0.634 & 0.649 & 0.709 & -0.469 & $46.69^{\text {***** }}$ & Type II \\
\hline 14 & Illinois & $4.238^{* * * *}$ & $3.789^{* * * *}$ & $3.939^{* * *}$ & $2.749^{* * *}$ & $1.562^{*}$ & $1.500^{*}$ & 1.135 & $1.831^{* *}$ & $1.184^{*}$ & 1.018 & $67.16^{* * * *}$ & Type II \\
\hline 15 & Indiana & $2.410^{* *}$ & $4.810^{\text {***** }}$ & $1.691^{* *}$ & -0.108 & $1.339^{*}$ & $1.631^{* *}$ & 0.783 & 0.986 & $1.762^{* * *}$ & 0.978 & $41.91^{\text {**** }}$ & Type II \\
\hline 16 & Iowa & $3.345^{\text {***** }}$ & 1.009 & $-1.223^{*}$ & $-1.656^{* *}$ & -0.336 & 0.786 & 0.783 & 0.353 & 0.413 & 0.494 & $18.32^{* *}$ & Type II \\
\hline 17 & Kansas & $6.859^{* * * * *}$ & $4.702^{* * * *}$ & $6.560^{\text {***** }}$ & $2.092^{* *}$ & 0.566 & 0.611 & $-1.647^{* *}$ & $1.763^{* *}$ & $3.697^{* * *}$ & $1.935^{* * *}$ & $140.50^{* * * *}$ & Type I \\
\hline 18 & Kentucky & $2.003^{* * *}$ & $4.127^{* * * *}$ & $3.738^{* * * *}$ & $3.251^{\text {**** }}$ & $1.236^{*}$ & $1.371^{*}$ & 1.018 & $1.518^{*}$ & 0.716 & 0.194 & $52.89^{* * * *}$ & Type II \\
\hline 19 & Louisiana & -0.420 & 0.872 & 0.927 & 0.093 & 0.249 & 0.277 & -0.201 & -0.772 & -1.152 & $-1.261^{*}$ & 5.50 & Time Reversible \\
\hline 20 & Maine & $1.871^{* * *}$ & $4.621^{* * * *}$ & $3.246^{* * * *}$ & $1.815^{* *}$ & $3.015^{\text {***** }}$ & $2.255^{* *}$ & $1.619^{*}$ & -0.219 & -0.161 & 0.055 & $55.58^{\text {***** }}$ & Type II \\
\hline 21 & Maryland & $2.932^{* * * *}$ & $1.429^{*}$ & 1.055 & $1.467^{*}$ & $1.904^{*}$ & $3.167^{* * * *}$ & $3.298^{* * * *}$ & $3.283^{* * * *}$ & $2.135^{* *}$ & $1.659^{* * *}$ & $56.52^{* * * *}$ & Type II \\
\hline 22 & Massachusetts & $4.809^{\text {****** }}$ & $4.169^{* * * *}$ & $5.217^{* * * * *}$ & $4.779^{* * * *}$ & $4.696^{* * * * *}$ & $4.777^{\text {***** }}$ & $7.225^{* * * *}$ & $7.215^{* * * *}$ & $6.985^{* * *}$ & $6.790^{* * * *}$ & $334.58^{\text {***** }}$ & Type II \\
\hline 23 & Michigan & $11.895^{\text {*****}}$ & $18.991^{* * * *}$ & $5.203^{\text {**** }}$ & $7.901^{* * * *}$ & -0.022 & $1.439^{*}$ & 0.918 & $3.736^{* * * *}$ & $2.866^{* * *}$ & $-1.478^{*}$ & $618.94^{* * * *}$ & Type II \\
\hline 24 & Minnesota & $2.790^{* * * *}$ & $3.144^{* * * *}$ & $2.901^{* *}$ & $2.620^{* *}$ & $1.702^{*}$ & 1.191 & 0.973 & 0.885 & $1.579^{\text {*** }}$ & 1.095 & $42.68^{\text {***** }}$ & Type II \\
\hline 25 & Mississippi & $1.525^{*}$ & $3.680^{* * * *}$ & $2.179^{* * *}$ & 0.654 & 1.203 & $1.691^{* *}$ & $2.710^{\text {***** }}$ & $1.915^{* *}$ & $1.381^{*}$ & $-1.546^{*}$ & $40.65^{\text {***** }}$ & Type II \\
\hline 26 & Missouri & -0.534 & 1.069 & $1.391^{*}$ & $1.506^{*}$ & 0.968 & -0.013 & -0.112 & $-1.505^{*}$ & -0.332 & -0.194 & 8.99 & Time Reversible \\
\hline
\end{tabular}

Notes: ${ }^{1}$ Time reversibility test is implemented on the change in U.S. states unemployment rates. The period studies for all the states are 1978:Q1 to 2004:Q3 except the unemployment rates for California are from 1980:Q1 to 2004:Q3.

${ }^{2}$ Standardized time reversibility test statistics where the standard deviation of the TR test statictics are estimated via Monte Carlo Simulation.

${ }^{3} \mathrm{P}_{1,10}$ is the time reversibility portmantaeu statistic which provides a joint test on a set of standardized TR test statistic values.

With 10 degree of freedom, $\chi_{0.90}^{2}=15.99, \chi_{0.95}^{2}=18.31$, and $\chi_{0.99}^{2}=23.20$.

${ }^{4}$ Type I rejection is the time irreversbility due to non-linear but Gaussian innovation, Type II rejection is time irreversiblity

due to linear but non-Gaussian innovation, and Time reversiblity indicates symmetry.

${ }^{5} *$ Indicates significance at the $10 \%$ level, $* *$ Indicates significance at the 5\% level, and *** Indicates significance at the $1 \%$ level. 
Table 2 (Cont.)

Standardized Time Reversibility Test Statistics on Quarterly U.S. StatesUnemployement Rates 1978:Q1 to 2004:Q3 ${ }^{1}$

\begin{tabular}{|c|c|c|c|c|c|c|c|c|c|c|c|c|c|}
\hline & \multirow[b]{2}{*}{ States } & \multicolumn{9}{|c|}{ Standardized TR test statistic at Lag $k^{2}$} & \multirow[b]{2}{*}{$k=10$} & \multirow[b]{2}{*}{$P_{1,10}{ }^{3}$} & \multirow{2}{*}{$\begin{array}{c}\text { Rejection } \\
\text { Type }^{4}\end{array}$} \\
\hline & & $k=1$ & $k=2$ & $k=3$ & $k=4$ & $k=5$ & $k=6$ & $k=7$ & $k=8$ & $k=9$ & & & \\
\hline 27 & Montana & $-1.782^{* * *}$ & 0.236 & -0.221 & -1.209 & -1.019 & -0.807 & -1.180 & 0.143 & 0.116 & 0.534 & 8.15 & Time Reversible \\
\hline 28 & Nebraska & $3.869^{* * * *}$ & $2.591^{* * * *}$ & $2.053^{* * *}$ & 1.101 & $2.396^{* * *}$ & $1.314^{*}$ & -0.119 & -0.650 & -0.124 & 0.709 & $35.53^{* * * *}$ & Type II \\
\hline 29 & Nevada & $2.749^{* * *}$ & $2.379^{* *}$ & $1.915^{* * *}$ & $2.480^{* * *}$ & $2.313^{* *}$ & $2.944^{\text {**** }}$ & $1.833^{* *}$ & 0.100 & 1.042 & 0.649 & $41.93^{* * * *}$ & Type II \\
\hline 30 & New Hampshire & $1.354^{*}$ & $1.935^{* *}$ & $1.515^{*}$ & $1.772^{\text {**** }}$ & $1.324^{*}$ & $1.271^{*}$ & $1.278^{*}$ & 0.393 & 1.094 & 1.027 & $18.42^{* *}$ & Type II \\
\hline 31 & New Jersey & 0.746 & $3.732^{* * * *}$ & $1.586^{*}$ & $1.389^{*}$ & $3.495^{\text {**** }}$ & $3.040^{* * * *}$ & $1.667^{* *}$ & 0.850 & $1.918^{* * *}$ & $3.505^{\text {**** }}$ & $59.85^{* * * *}$ & Type II \\
\hline 32 & New Mexico & $7.042^{* * * *}$ & $2.330^{* *}$ & $3.070^{* * * * *}$ & $2.990^{* * * *}$ & $2.550^{* * *}$ & $1.746^{* * *}$ & $1.327^{*}$ & 0.192 & -0.375 & -0.239 & $84.92^{* * * *}$ & Type II \\
\hline 33 & New York & $3.208^{* * * *}$ & 0.776 & $1.616^{* *}$ & 0.273 & 0.433 & 0.961 & 0.804 & 0.983 & 0.606 & 0.005 & $16.67^{*}$ & Type II \\
\hline 34 & North Carolina & $-6.440^{* * * *}$ & $-1.623^{* * *}$ & $-1.336^{*}$ & $-1.344^{*}$ & $1.732^{* *}$ & $5.553^{* * * *}$ & $5.390^{* * *}$ & $5.125^{* * * *}$ & $3.796^{* * * *}$ & $1.750^{* * *}$ & $154.36^{* * * * *}$ & Type II \\
\hline 35 & North Dakota & $1.627^{*}$ & -0.297 & 0.514 & -0.602 & 0.178 & $-1.260^{*}$ & -0.683 & $-3.194^{* * * *}$ & $-1.88^{* * *}$ & 0.358 & $19.30^{* *}$ & Type II \\
\hline 36 & Ohio & 0.496 & $3.791^{* * * *}$ & $1.672^{* *}$ & $1.843^{* *}$ & $2.246^{* *}$ & $2.917^{* * * *}$ & $3.165^{* * *}$ & 1.102 & $1.831^{* *}$ & $1.489^{*}$ & $51.16^{* * * *}$ & Type II \\
\hline 37 & Oklahoma & $5.807^{* * *}$ & $5.260^{\text {***** }}$ & $3.513^{* * *}$ & $2.618^{* * * *}$ & $1.323^{*}$ & -0.620 & $-3.272^{\text {**** }}$ & $-4.464^{* * * *}$ & $-2.289^{* * *}$ & 0.209 & $118.64^{\text {**** }}$ & Type II \\
\hline 38 & Oregon & -0.492 & $2.733^{\text {***** }}$ & 1.194 & 0.055 & 0.357 & 0.024 & 0.937 & $1.291^{*}$ & $1.893^{* * *}$ & 0.976 & $16.34^{*}$ & Type II \\
\hline 39 & Pennsylvania & $5.505^{* * * *}$ & $7.705^{* * * *}$ & $7.486^{* * * *}$ & $6.680^{* * * *}$ & $6.032^{* * * *}$ & $4.990^{* * * *}$ & $3.762^{* * * *}$ & $2.568^{* *}$ & $2.363^{* * *}$ & $2.198^{* * *}$ & $282.77^{\text {***** }}$ & Type II \\
\hline 40 & Puerto Rico & 0.631 & 0.209 & -0.121 & 0.572 & -0.209 & $1.277^{*}$ & -0.129 & $1.894^{* *}$ & 0.663 & $2.294^{* * *}$ & 11.766 & Time Reversible \\
\hline 41 & Rhode Island & 1.048 & 0.223 & $2.292^{* * *}$ & $2.676^{* * * *}$ & $2.664^{* * * *}$ & $2.816^{* * * *}$ & $2.071^{* *}$ & $1.231^{*}$ & $1.250^{*}$ & $2.636^{* * *}$ & $42.90^{* * * *}$ & Type II \\
\hline 42 & South Carolina & $3.096^{* * * *}$ & $2.045^{* *}$ & 0.802 & 0.722 & $1.522^{*}$ & $1.570^{*}$ & $1.503^{*}$ & 1.146 & $1.231^{*}$ & $1.136^{*}$ & $26.09^{* * * *}$ & Type II \\
\hline 43 & South Dakota & 0.849 & $1.645^{* *}$ & $2.084^{* * *}$ & $2.472^{* * * *}$ & -0.511 & -1.190 & -1.090 & 0.743 & 0.621 & 0.861 & $18.42^{* *}$ & Type II \\
\hline 44 & Tennessee & $3.283^{* * *}$ & $2.070^{* *}$ & $2.333^{* * *}$ & $2.032^{* * *}$ & $3.051^{* * * *}$ & $3.584^{\text {**** }}$ & $3.462^{* * * *}$ & $3.642^{* * * *}$ & $3.238^{* * *}$ & $2.336^{* * *}$ & $87.98^{\text {**** }}$ & Type II \\
\hline 45 & Texas & $1.975^{* *}$ & $1.257^{*}$ & $2.181^{* *}$ & $2.231^{* * *}$ & $2.322^{* *}$ & $2.183^{* *}$ & $1.285^{*}$ & 0.134 & -0.837 & -1.093 & $28.93^{* * * *}$ & Type II \\
\hline 46 & Utah & $4.766^{* * * *}$ & $6.432^{* * * *}$ & $6.218^{* * * *}$ & $5.502^{* * * *}$ & $3.456^{* * * * *}$ & $2.318^{* * *}$ & $1.581^{* * *}$ & 0.405 & 0.512 & 0.421 & $153.44^{\text {***** }}$ & Type II \\
\hline 47 & Vermont & $4.463^{* * * *}$ & $3.843^{* * * *}$ & $2.713^{* * *}$ & 0.918 & 0.028 & 0.843 & 0.169 & -0.083 & 0.467 & 0.898 & $44.66^{* * * *}$ & Type II \\
\hline 48 & Virginia & $4.511^{* * * *}$ & $3.385^{* * * *}$ & $2.312^{* * *}$ & $1.827^{\text {*** }}$ & $2.991^{* * * *}$ & $3.056^{* * * *}$ & $3.037^{\text {**** }}$ & $2.983^{* * * *}$ & $2.067^{* *}$ & $1.765^{* * *}$ & $84.27^{* * * *}$ & Type II \\
\hline 49 & Washington & $-2.110^{* * *}$ & 0.519 & 0.610 & 0.272 & $1.276^{*}$ & $1.562^{*}$ & $1.678^{*}$ & $1.607^{*}$ & $1.845^{* * *}$ & $1.579^{*}$ & $20.53^{* * *}$ & Type II \\
\hline 50 & West Virginia & $5.832^{\text {**** }}$ & $4.089^{\text {**** }}$ & $2.939^{* * *}$ & $2.890^{\text {**** }}$ & $2.248^{* *}$ & $2.423^{* *}$ & $2.642^{* *}$ & $2.273^{* *}$ & $2.714^{* * *}$ & $3.566^{\text {***** }}$ & $110.86^{* * * *}$ & Type II \\
\hline 51 & Wisconsin & $6.686^{* * * *}$ & $5.460^{* * * *}$ & $2.583^{* * * *}$ & $3.508^{* * * *}$ & $1.962^{* *}$ & $2.559^{* * *}$ & $2.632^{\text {**** }}$ & $1.613^{*}$ & $1.369^{*}$ & -0.233 & $115.34^{\text {***** }}$ & Type II \\
\hline 52 & Wyoming & $7.206^{* * * *}$ & $7.088^{\text {****** }}$ & $4.896^{* * * *}$ & $5.831^{\text {***** }}$ & $4.148^{* * * * *}$ & $1.651^{* * *}$ & 0.637 & 0.972 & -0.317 & -0.865 & $182.27^{\text {***** }}$ & Type II \\
\hline
\end{tabular}

Notes: ${ }^{1}$ Time reversibility test is implemented on the change in U.S. states unemployment rates. The period studies for all the states are 1978:Q1 to 2004:Q3 except the unemployment rates for California are from 1980:Q1 to 2004:Q3.

${ }^{2}$ Standardized time reversibility test statistics where the standard deviation of the TR test statictics are estimated via Monte Carlo Simulation.

${ }^{3} \mathrm{P}_{1,10}$ is the time reversibility portmantaeu statistic which provides a joint test on a set of standardized TR test statistic values.

With 10 degree of freedom, $\chi_{0.90}^{2}=15.99, \chi_{0.95}^{2}=18.31$, and $\chi_{0.99}^{2}=23.20$.

${ }^{4}$ Type I rejection is the time irreversbility due to non-linear but Gaussian innovation, Type II rejection is time irreversiblity due to linear but non-Gaussian innovation, and Time reversibility indicates the symmetry.

$5 *$ Indicates significance at the $10 \%$ level, ** Indicates significance at the $5 \%$ level, and *** Indicates significance at the $1 \%$ level. 
Table 3

Standardized Time Reversibility Test Statistics for ARMA Residuals for U.S. State Unemployement Rates 1978:Q1 to 2004:Q3 ${ }^{1}$

\begin{tabular}{|c|c|c|c|c|c|c|c|c|c|c|c|c|c|}
\hline & \multirow[b]{2}{*}{ States } & \multicolumn{9}{|c|}{ Standardized TR test statistic at Lag $k^{2}$} & \multirow[b]{2}{*}{$k=10$} & \multirow[b]{2}{*}{$\mathrm{P}_{1,10}{ }^{3}$} & \multirow{2}{*}{$\begin{array}{c}\text { Rejection } \\
\text { Type }^{4}\end{array}$} \\
\hline & & $k=1$ & $k=2$ & $k=3$ & $k=4$ & $k=5$ & $k=6$ & $k=7$ & $k=8$ & $k=9$ & & & \\
\hline 1 & Alabama & -0.041 & $1.136^{* *}$ & 0.347 & -0.348 & 0.421 & 0.658 & 0.061 & 0.725 & 0.600 & 0.517 & 3.299 & Type II \\
\hline 2 & Alaska & -0.623 & 0.314 & 0.015 & -0.695 & 0.122 & 0.215 & 0.952 & -0.251 & 0.112 & -0.651 & 2.437 & Time Reversible \\
\hline 3 & Arizona & 0.046 & -0.029 & 0.588 & 0.200 & 0.138 & -0.103 & -0.077 & -0.041 & 0.066 & -0.041 & 0.432 & Type II \\
\hline 4 & Arkansas & $-3.074^{* * *}$ & 0.624 & 1.167 & -0.292 & 0.695 & -0.246 & -0.641 & -0.252 & 0.190 & -0.337 & 12.455 & Type II \\
\hline 5 & California & $2.348^{* * *}$ & $3.400^{* * *}$ & -0.855 & $-8.468^{* * *}$ & $3.214^{* * * *}$ & $9.558^{* * * *}$ & $2.604^{* *}$ & $3.882^{* * * *}$ & $3.682^{* * * *}$ & -0.994 & $227.61^{* * *}$ & Type I \\
\hline 6 & Colorado & 0.285 & $1.835^{* *}$ & -0.719 & 0.832 & 0.383 & 0.343 & -0.819 & -0.028 & 0.785 & -0.118 & 6.222 & Type II \\
\hline 7 & Connecticut & $1.493^{*}$ & 0.849 & 0.128 & -0.160 & 1.001 & 1.052 & 0.753 & 0.388 & 0.537 & 0.781 & 6.717 & Type II \\
\hline 8 & Delaware & 0.587 & $1.518^{*}$ & 0.226 & 0.223 & 1.128 & 0.900 & 0.452 & 0.968 & 0.105 & -0.245 & 6.046 & Type II \\
\hline 9 & Columbia & -0.369 & -0.800 & 0.113 & 0.538 & 0.838 & $1.437^{*}$ & 0.000 & -0.113 & -0.434 & 0.110 & 4.059 & Time Reversible \\
\hline 10 & Florida & 0.870 & $1.583^{*}$ & 1.071 & $1.409^{*}$ & 0.422 & 0.547 & $1.324^{*}$ & 0.957 & 0.712 & -0.023 & 10.049 & Type II \\
\hline 11 & Georgia & $2.138^{* *}$ & 0.870 & $-3.373^{* * * *}$ & 0.976 & 1.135 & 0.693 & 0.670 & 0.526 & 0.418 & -0.231 & $20.376^{* *}$ & Type I \\
\hline 12 & Hawaii & $2.184^{* *}$ & 0.079 & -0.091 & 0.417 & -0.208 & -0.404 & -0.631 & -0.097 & 0.044 & -0.145 & 5.597 & Time Reversible \\
\hline 13 & Idaho & -0.738 & $2.589^{* * *}$ & 0.442 & 0.821 & 1.114 & -0.068 & 0.259 & 0.578 & -0.729 & -0.012 & 10.294 & Type II \\
\hline 14 & Illinois & -0.357 & 0.212 & 0.742 & $1.282^{*}$ & -0.322 & 0.389 & -0.367 & 1.052 & 0.568 & 0.289 & 4.271 & Type II \\
\hline 15 & Indiana & 0.131 & $2.440^{* * *}$ & 0.105 & -0.367 & 0.473 & 0.487 & -0.080 & 0.066 & 0.676 & 0.118 & 7.056 & Type II \\
\hline 16 & Iowa & -0.655 & $1.231^{*}$ & -0.379 & -0.689 & -0.190 & 0.046 & 0.096 & 0.495 & 0.521 & 0.105 & 3.138 & Type II \\
\hline 17 & Kansas & $2.930^{* * *}$ & 1.196 & $1.590^{* *}$ & -0.324 & 0.258 & 0.838 & -0.427 & 0.681 & 0.979 & $1.344^{*}$ & $16.828^{*}$ & Type I \\
\hline 18 & Kentucky & 0.347 & 0.168 & 0.117 & -0.602 & -0.033 & 0.886 & 0.736 & 0.710 & 0.150 & -0.226 & 2.432 & Type II \\
\hline 19 & Louisiana & 0.403 & -0.112 & -0.196 & -0.650 & -0.234 & 0.130 & 0.043 & -0.047 & -0.205 & -0.096 & 0.763 & Time Reversible \\
\hline 20 & Maine & $1.243^{*}$ & $1.259^{*}$ & 0.730 & 0.245 & 0.485 & 0.214 & 0.333 & 0.426 & -0.090 & -0.170 & 4.336 & Type II \\
\hline 21 & Maryland & 1.056 & 0.029 & 0.124 & 0.355 & $1.306^{*}$ & 0.756 & $1.349^{*}$ & 0.878 & 0.800 & 0.156 & 6.790 & Type II \\
\hline 22 & Massachusetts & 1.070 & 0.668 & 0.707 & 0.036 & 0.476 & 0.471 & 1.005 & 0.939 & 0.016 & 0.808 & 5.086 & Type II \\
\hline 23 & Michigan & 0.455 & 0.411 & -0.302 & 0.382 & -0.046 & 0.539 & 0.407 & 0.496 & 0.155 & 0.409 & 1.509 & Type II \\
\hline 24 & Minnesota & 0.725 & 0.058 & 0.437 & 0.796 & -0.129 & 0.385 & 0.237 & 0.244 & 0.264 & 0.088 & 1.711 & Type II \\
\hline 25 & Mississippi & 0.204 & $2.205^{* *}$ & 1.112 & -0.097 & 0.959 & $1.347^{*}$ & $1.879^{* *}$ & -0.120 & 1.119 & -1.331 & 15.452 & Type II \\
\hline 26 & Missouri & 0.570 & 0.168 & 0.142 & -0.167 & 0.001 & -0.549 & 0.324 & -0.038 & -0.104 & -0.209 & 0.864 & Time Reversible \\
\hline
\end{tabular}

Notes: ${ }^{1}$ Time reversibility test is implemented on the ARMA residuals derived from fitting the ARMA model to U.S. state unemployment rates. The period studies for all the states are from 1978:Q1 to 2004:Q3 except the unemployment rates for California are from 1980:Q1 to 2004:Q3.

${ }^{2}$ Standardized time reversibility test statistics where the standard deviation of the TR test statictics are estimated via equation (3).

${ }^{3} \mathrm{P}_{1,10}$ is the time reversibility portmantaeu statistic which provides a joint test on a set of standardized TR test statistic values. With 10 degree of freedom, $\chi_{0.90}^{2}=15.99, \chi_{0.95}^{2}=18.31$, and $\chi_{0.99}^{2}=23.20$.

${ }^{4}$ Type I rejection is the time irreversbility due to non-linear but Gaussian innovation, Type II rejection is time irreversiblity due to linear but non-Gaussian innovation, and time reversibility indicates symmetry.

${ }^{5} *$ Indicates significance at the $10 \%$ level, ** Indicates significance at the $5 \%$ level, and *** Indicates significance at the $1 \%$ level. 
Table 3 (Cont.)

Standardized Time Reversibility Test Statistics for ARMA Residuals for U.S. State Unemployement Rates 1978:Q1 to 2004:Q3 ${ }^{1}$

\begin{tabular}{|c|c|c|c|c|c|c|c|c|c|c|c|c|c|}
\hline & \multirow[b]{2}{*}{ States } & \multicolumn{10}{|c|}{ Standardized TR test statistic at Lag $k^{2}$} & \multirow[b]{2}{*}{$P_{1,10}^{3}$} & \multirow{2}{*}{$\begin{array}{c}\text { Rejection } \\
\text { Type }^{4}\end{array}$} \\
\hline & & $k=1$ & $k=2$ & $k=3$ & $k=4$ & $k=5$ & $k=6$ & $k=7$ & $k=8$ & $k=9$ & $k=10$ & & \\
\hline 27 & Montana & -0.442 & -0.409 & -0.072 & -0.398 & -0.178 & 0.567 & -0.006 & 0.316 & 0.184 & 0.083 & 1.019 & Time Reversible \\
\hline 28 & Nebraka & $1.302^{*}$ & -0.778 & 1.036 & -0.786 & $2.356^{* *}$ & 0.106 & $-2.294^{* *}$ & 0.807 & -0.144 & 0.432 & 15.672 & Type II \\
\hline 29 & Nevada & 0.926 & -0.111 & -0.276 & 0.576 & 0.445 & $2.309^{* *}$ & 0.316 & -0.114 & -0.124 & -0.364 & 7.068 & Type II \\
\hline 30 & New Hampshire & 0.016 & 0.653 & 0.288 & 0.363 & 0.224 & 0.083 & 0.438 & -0.280 & 0.781 & 0.647 & 1.998 & Type II \\
\hline 31 & New Jersey & 0.761 & $1.932^{* *}$ & 0.519 & 0.056 & 1.077 & 0.314 & 0.288 & 1.042 & 0.577 & $1.230^{* *}$ & 8.857 & Type II \\
\hline 32 & New Mexico & 0.764 & 0.362 & 1.148 & 1.066 & -0.121 & 0.771 & 0.335 & 0.351 & 0.080 & -0.019 & 4.019 & Type II \\
\hline 33 & New York & 0.772 & -0.177 & 0.740 & -0.484 & 0.147 & -0.502 & 0.297 & 0.462 & -0.285 & -0.444 & 2.264 & Type II \\
\hline 34 & North Carolina & 0.753 & 1.091 & -0.275 & $-2.573^{* *}$ & 0.979 & $2.916^{* * *}$ & 0.796 & 1.189 & 1.130 & -0.306 & $21.34^{* *}$ & Type I \\
\hline 35 & North Dakota & -0.110 & -0.689 & -0.188 & -0.198 & 0.108 & -0.019 & 0.646 & -0.143 & 1.174 & 0.030 & 2.389 & Type II \\
\hline 36 & Ohio & -0.318 & -0.022 & -0.655 & -0.366 & 0.437 & 0.633 & 0.567 & 0.356 & 0.482 & 0.600 & 2.297 & Type II \\
\hline 37 & Oklahoma & 1.006 & 0.296 & 0.345 & -0.309 & -0.128 & -0.373 & -1.018 & $-1.540^{*}$ & -0.372 & 0.281 & 5.096 & Type II \\
\hline 38 & Oregon & 0.261 & $1.555^{*}$ & 0.305 & -0.334 & -0.374 & -0.306 & 1.212 & 0.892 & 0.754 & -0.327 & 5.863 & Type II \\
\hline 39 & Pennsylvania & 0.143 & 0.773 & 1.166 & -0.279 & 0.438 & 1.487 & 0.331 & 0.466 & 1.163 & -0.258 & 6.210 & Type II \\
\hline 40 & Puerto Rico & $1.511^{*}$ & 0.910 & -0.212 & 0.510 & -0.642 & 0.910 & 0.694 & 1.213 & $1.391^{*}$ & $1.404^{*}$ & 10.516 & Time Reversible \\
\hline 41 & Rhode Island & 0.246 & 0.055 & 0.648 & 0.147 & 0.092 & 0.548 & -0.246 & -0.463 & -0.146 & 1.120 & 2.364 & Type II \\
\hline 42 & South Carolina & 1.083 & 0.506 & 0.200 & 0.203 & 0.531 & 0.578 & 0.979 & 0.208 & 0.544 & 0.300 & 3.512 & Type II \\
\hline 43 & South Dakota & -0.558 & 0.495 & 0.366 & 1.100 & 0.197 & 0.212 & 0.248 & 0.242 & 0.291 & -0.345 & 2.309 & Type II \\
\hline 44 & Tennessee & -0.358 & 0.876 & 0.371 & 0.079 & 1.024 & 0.843 & 0.319 & 0.704 & 0.632 & 0.462 & 4.010 & Type II \\
\hline 45 & Texas & 0.258 & 1.174 & 0.046 & 0.526 & 0.164 & 0.399 & 0.203 & -0.225 & 0.227 & -0.201 & 2.094 & Type II \\
\hline 46 & Utah & -0.434 & 0.140 & 0.512 & $1.566^{*}$ & 0.303 & 0.338 & 0.253 & 0.175 & 0.579 & 0.421 & 3.734 & Type II \\
\hline 47 & Vermont & $1.277^{*}$ & -0.085 & $1.908^{* *}$ & 0.846 & 0.322 & 1.043 & 0.010 & 0.328 & $1.191^{*}$ & $1.349^{*}$ & 10.533 & Type II \\
\hline 48 & Virginia & $1.467^{*}$ & 1.143 & 0.120 & 0.496 & $1.621^{*}$ & 0.772 & 0.566 & 0.877 & 0.226 & 0.050 & 8.087 & Type II \\
\hline 49 & Washington & $-1.253^{*}$ & -0.188 & 0.343 & -0.045 & 0.250 & -0.005 & -0.029 & 0.020 & 0.556 & 0.087 & 2.107 & Type II \\
\hline 50 & West Virginia & 0.719 & 0.609 & -0.821 & $1.531^{*}$ & 0.274 & 0.019 & 0.451 & $1.623^{*}$ & 1.059 & 0.208 & 7.984 & Type II \\
\hline 51 & Wisconsin & 0.508 & $1.851^{* *}$ & -0.248 & $1.230^{*}$ & 0.941 & 0.966 & $1.423^{*}$ & 0.153 & 0.523 & -0.368 & 9.537 & Type II \\
\hline 52 & Wyoming & -0.349 & 1.127 & 0.086 & $1.886^{* *}$ & $1.916^{* *}$ & 0.181 & 0.199 & 0.655 & 0.055 & -0.252 & 9.196 & Type II \\
\hline
\end{tabular}

Notes: ${ }^{1}$ Time reversibility test is implemented on the ARMA residuals derived from fitting the ARMA model to U.S. state unemployment rates.

The period studies for all the states are from 1978:Q1 to 2004:Q3 except the unemployment rates for California are from 1980:Q1 to 2004:Q3.

${ }^{2}$ Standardized time reversibility test statistics where the standard deviation of the TR test statictics are estimated via equation (3).

${ }^{3} \mathrm{P}_{1,10}$ is the time reversibility portmantaeu statistic which provides a joint test on a set of standardized TR test statistic values.

With 10 degree of freedom, $\chi_{0.90}^{2}=15.99, \chi_{0.95}^{2}=18.31$, and $\chi_{0.99}^{2}=23.20$.

${ }^{4}$ Type I rejection is the time irreversbility due to non-linear but Gaussian innovation, Type II rejection is time irreversiblity due to linear but non-Gaussian innovation, and Time reversiblity indicates symmetry.

${ }^{5} *$ Indicates significance at the $10 \%$ level, $* *$ Indicates significance at the $5 \%$ level, and $* * *$ Indicates significance at the $1 \%$ level. 


\section{NOTES}

